\title{
Genetic deficiency of neuronal RAGE protects against AGE-induced synaptic injury
}

\author{
Hongju Zhang ${ }^{1,2,3}$, Yongfu Wang ${ }^{1,3}$, Shijun Yan ${ }^{1}$, Fang $\mathrm{Du}^{1}$, Long Wu${ }^{1}$, Shiqiang Yan $^{2}$ and Shirley S Yan ${ }^{\star, 1}$
}

Synaptic dysfunction and degeneration is an early pathological feature of aging and age-related diseases, including Alzheimer's disease (AD). Aging is associated with increased generation and deposition of advanced glycation endproducts (AGEs), resulting from nonenzymatic glycation (or oxidation) proteins and lipids. AGE formation is accelerated in diabetes and ADaffected brain, contributing to cellular perturbation. The extent of AGEs' involvement, if at all, in alterations in synaptic structure and function is currently unknown. Here we analyze the contribution of neuronal receptor of AGEs (RAGE) signaling to AGEmediated synaptic injury using novel transgenic neuronal RAGE knockout mice specifically targeted to the forebrain and transgenic mice expressing neuronal dominant-negative RAGE (DN-RAGE). Addition of AGEs to brain slices impaired hippocampal long-term potentiation (LTP). Similarly, treatment of hippocampal neurons with AGEs significantly decreases synaptic density. Such detrimental effects are largely reversed by genetic RAGE depletion. Notably, brain slices from mice with neuronal RAGE deficiency or DN-RAGE are resistant to AGE-induced LTP deficit. Further, RAGE deficiency or DN-RAGE blocks AGE-induced activation of $\mathrm{p} 38$ signaling. Taken together, these data show that neuronal RAGE functions as a signal transducer for AGE-induced synaptic dysfunction, thereby providing new insights into a mechanism by which the AGEs-RAGE-dependent signaling cascade contributes to synaptic injury via the p38 MAP kinase signal transduction pathway. Thus, RAGE blockade may be a target for development of interventions aimed at preventing the progression of cognitive decline in aging and age-related neurodegenerative diseases.

Cell Death and Disease (2014) 5, e1288; doi:10.1038/cddis.2014.248; published online 12 June 2014

Advanced glycation endproducts (AGEs) are members of a heterogeneous class of molecules, which modify cellular function by distinct mechanisms, including ligation and activation of signal transduction receptors. The products of non-enzymatic glycation (or oxidation) of proteins and lipids, AGEs contribute to the normal aging process and when accelerated have a causative role in the vasculature complications of diabetes mellitus and several neurodegenerative diseases, including Alzheimer's (AD), Parkinson's, and Huntington's diseases. ${ }^{1-5}$ In diabetic patients, the concentration of circulating AGEs (serum AGE level) has been reported at $7.2-22 \mathrm{mU} / \mathrm{ml}$ (equivalent to $30-88 \mu \mathrm{g} / \mathrm{ml}$ AGE-BSA), which is significantly higher than that of non-diabetic patients $(3 \mathrm{mU} / \mathrm{ml}$, equivalent to $12 \mu \mathrm{g} / \mathrm{ml}$ AGE-BSA). ${ }^{6-8}$ The brain AGE level was also increased to 5-6 $\mu \mathrm{M}$ (equivalent to $325-390 \mu \mathrm{g} / \mathrm{ml}$ AGE-BSA) in the diabetic animal model. ${ }^{9}$ Excess AGE accumulation is detrimental to neurons and is believed to be a key to the pathogenesis of cognitive decline in normal aging and specific chronic diseases of aging. For example, in a recent clinical study, peripheral AGE levels were associated with cognitive decline in older adults with and without diabetes. ${ }^{10}$ Diabetes complications affect the brain, increasing risk for depression, dementia, and AD. In fact, patients with type 2 diabetes are at twofold to threefold increased relative risk for $A D^{11-18}$ and accelerated cognitive dysfunction.

Long-lived proteins such as $\beta$-amyloid peptide $(\mathrm{A} \beta)$ and hyperphosphorylated tau protein that accumulate in AD brain are highly susceptible to AGE modification. ${ }^{19-22}$ AGEmodified $\mathrm{A} \beta$ or tau protein results in increased oxidative stress and chronic inflammation, accelerating $A D$ pathology and neuronal perturbation. ${ }^{19,20,22-25}$ Moreover, $\mathrm{A} \beta$ or tau glycation results in increased aggregation and subsequent formation of senile plaques or neurofibrillary tangles, the major pathological feature of $A D,{ }^{19,22}$ suggesting that $A G E$ modification is an important risk factor for neurodegenerative diseases. ${ }^{26}$ Although increased accumulation of AGEs in brain, as seen in aging, diabetes, or neurodegenerative diseases, speeds up oxidative damage to neurons contributing to synaptic dysfunction and cognitive decline, its underlying mechanisms are not well understood.

Receptor for advanced glycation endproduct (RAGE) was first identified as a cell surface receptor of the immunoglobulin superfamily for AGEs. ${ }^{27,28}$ Increased expression of RAGE

\footnotetext{
${ }^{1}$ Departments of Pharmacology and Toxicology and Higuchi Bioscience Center, School of Pharmacy, University of Kansas, Lawrence, KS 66047, USA and ${ }^{2}$ School of Chemistry and Chemical Engineering, Lanzhou University, Lanzhou, Gansu 730000, China

${ }^{*}$ Corresponding author: SS Yan, Departments of Pharmacology and Toxicology and Higuchi Bioscience Center, School of Pharmacy, University of Kansas, 2099 Constant Avenue, Lawrence, KS 66047, USA. Tel: +1 785864 3637; Fax: +1 785864 5219; E-mail: shidu@ku.edu

${ }^{3}$ These authors contributed equally to this work.

Abbreviations: aCSF, artificial cerebrospinal fluid; AD, Alzheimer's disease; AGEs, advanced glycation endproducts; CK2, calcium-calmodulin-dependent kinase II; CML, Ne-carboxymethyl-lysine; DN-RAGE, dominant-negative RAGE; fEPSP, field-excitatory post-synaptic potential; JNK, c-Jun N-terminal kinase; LTP, long-term potentiation; nRKO, neuronal RAGE selective knockout; p38 MAPK, p38 mitogen-activated protein kinase; RAGE, receptor for advanced glycation endproduct; RKO, global RAGE knockout

Received 11.3.14; revised 28.4.14; accepted 05.5.14; Edited by A Verkhratsky
} 
occurs in neuronal and non-neuronal cells in the peripheral and central nervous system in aging, diabetes, and ADaffected individuals, where RAGE ligands are upregulated. ${ }^{29,30}$ Although it has been shown that AGEs-RAGE interaction contributes to cellular perturbation relevant to the pathogenesis of the cardiovascular disease and the diabetes vascular complications, ${ }^{31-33}$ little is known about the role of AGEs and its interaction with RAGE on synaptic dysfunction. To understand the mechanisms involved in AGE-mediated synaptic damage, the following questions need to be addressed: (1) 'Do AGEs alter synaptic structure and function? If so, are these changes dependent on RAGE signaling?'; (2) 'Does RAGE blockage by genetic depletion protect from AGE-induced synaptic dysfunction and loss?'; and (3) 'What is the impact of neuronal RAGE in AGE-induced aberrant synaptic function?'. Thus it is important to evaluate the impact of AGEs-RAGE interaction on synaptic dysfunction and to explore the mechanism underlying AGE-RAGEdependent signal transduction and its contribution to synaptic damage.

Here we investigate neuronal RAGE signaling in AGEinduced synaptic injury using our novel conditional RAGE knockout mice targeted to cortical neurons as well as transgenic mice that overexpress signal transduction-deficient mutants of RAGE in neurons. Given that neuronal and non-neuronal cells in the brain may contribute to AGE-induced sustained neuronal and synaptic stress and dysfunction, we assessed the impact of global RAGE deletion in this setting and further delineated the mechanism by which RAGEdependent activation of p38 MAP kinase potentiates AGEinsulted synaptic injury.

\section{Results}

Generation and characterization of conditional neuronal RAGE selective knockout (nRKO) mice. We developed a model system in which neuronal expression of RAGE, in particular in the brain region responsible for learning and memory, is deleted so that consequences of receptor-ligand interaction could be assessed in an AGE-rich environment.
To this end, we have recently created Cre recombinase RAGE null mice, termed Tg nRKO mice, crossing neuronaltargeted and region-restricted $\mathrm{Tg}$ mice that express Cre recombinase in the entire forebrain under the control of the forebrain-specific calcium-calmodulin-dependent kinase II (CAMKIla, CK2) promoter ${ }^{34}$ to generate deletion of neuronal RAGE in the entire hippocampus and cortex. We used two Cre-loxP systems to generate the targeting vector and the RAGE/flox mice (performed by Ozgen Inc., Bentley DC, WA, Australia). Figure 1a demonstrates a targeting vector containing the $5^{\prime}$ homology arm, the $3^{\prime}$ homology arm, and loxP arm. Two loxP sites flanking RAGE exons 2-4 allow for Cre-mediated deletion using Cre recombinase (Figure 1b). Excision of exons $2-4$ by Cre recombinase results in a frame shift and early stop codon from the mouse RAGE sequence, which block RAGE expression. We first made homozygous RAGE floxed allele mice ( $R A G E^{\text {flox/flox }}$ ); then RAGE flox/flox mice were crossed with neuronal target CK2 mice to generate $\mathrm{nRKO}$ mice (RAGE $\left.{ }^{\text {flox/flox }} / C K 2-C r e\right)$, which were then verified by analysis of tail DNA with PCR amplication using primers for flox (700 bp) and Cre transgene (300 bp) (Figure 2a). Immunoblotting of cortical homogenates with anti-RAGE antibody showed significant reduction of RAGE expression levels in cerebral cortex of nRKO mice compared with non-Tg mice ( $\sim 80 \%$ reduction versus non-Tg brain, $P<0.01)$ (Figure 2b). Incomplete suppression of RAGE expression was due to brain homogenates, which contained non-neuronal cells. RAGE expression levels were not altered in cerebellum homogenates (Figure 2c). Confocal microscopy with double immunostaining of RAGE and MAP2 clearly demonstrated that there was virtually no RAGE signal in MAP2-positive neurons in cortex (Figures 2d-e) and hippocampus (Figure 2f) of $\mathrm{nRKO}$ mice, thereby verifying RAGE depletion in cortical neurons in the brain of $n R K O$ mice.

Immunochemical characterization of $\mathrm{N} \varepsilon$-carboxymethyllysine (CML) in AGE preparation. Of all forms of AGEs, $\mathrm{CML}$ is a major glycation product known to be stable and accumulate progressively in vivo in aging, $A D$, and
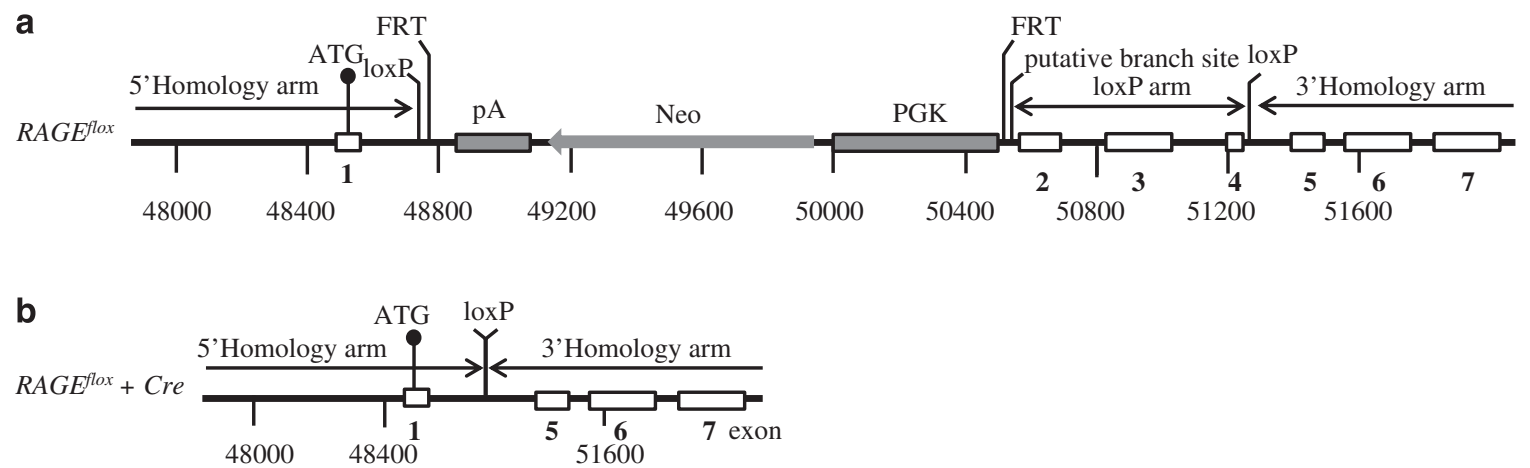

Figure 1 Targeted construct cassette. Schematic representation of the strategy used for conditional knockout of the RAGE gene by excision of exons 2-4 of the mouse RAGE gene. (a) Annotated (MacVector 9.5.3) display of the locus identifying the region targeted for homologous recombination. The targeting vector was constructed from three fragments, the $5^{\prime}$ homology arm, two loxP sites and the $3^{\prime}$ homology arm. PGK-neo selection cassette is inserted downstream of exon 1 . The PGK-neo cassette is flanked by FRT sites and exons 2-4 are flanked by two loxP sites. (b) RAGE ${ }^{\text {flox/flox }}$ mice were crossed with neuronal target CK2 mice to generate $\mathrm{nRKO}$ mice (RAGE ${ }^{\text {flox/flox} /}$ CK2-Cre). Two loxP sites flanking RAGE exons 2 to 4 to allow for Cre-mediated deletion using Cre-recombinase. Excision of exons $2-4$ by Cre recombinase leads to a frame shift and early stop codon from the mouse RAGE sequence to block RAGE expression 

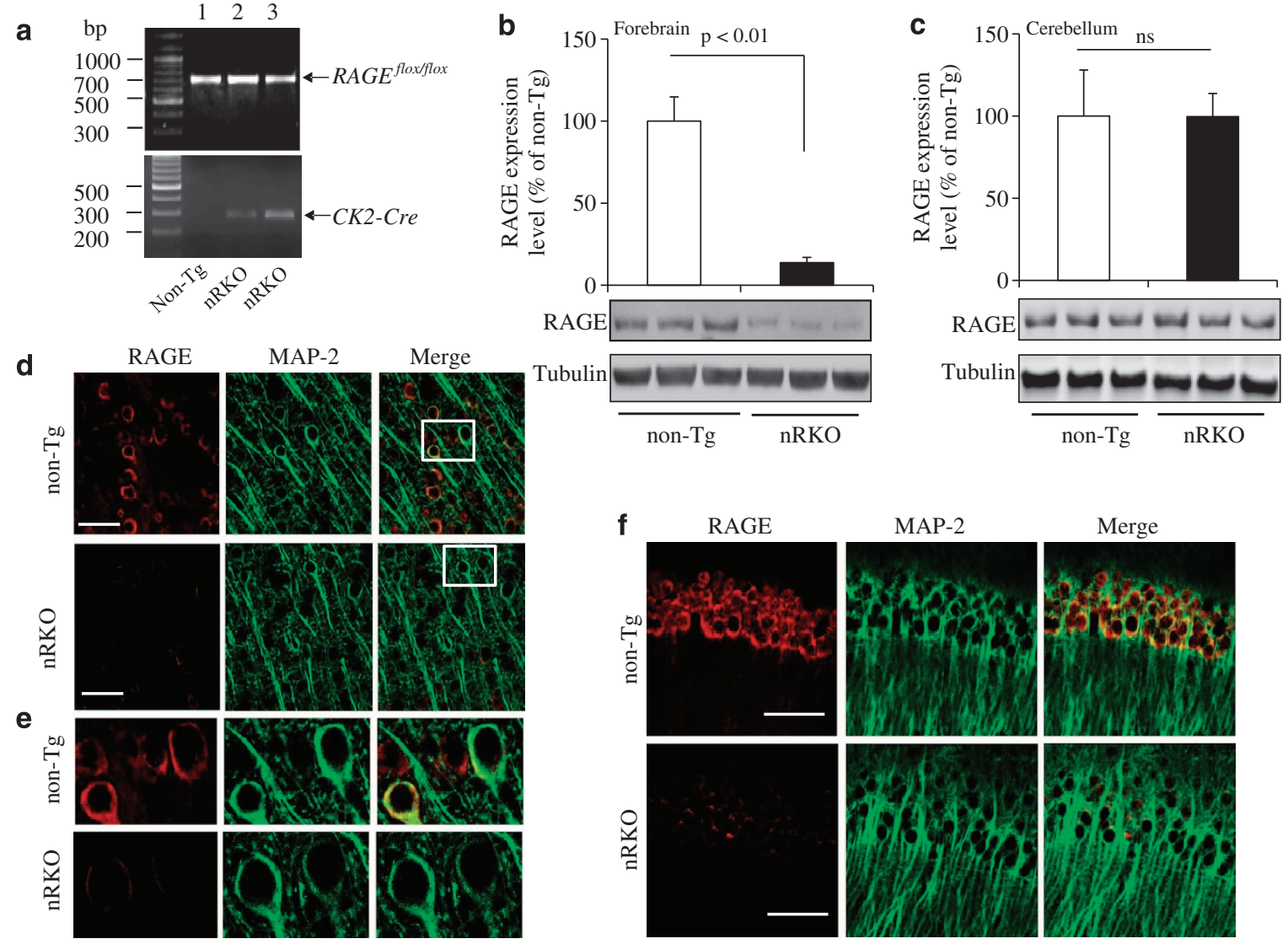

Figure 2 Characterization of transgenic nRKO mice with RAGE deletion in cortical neurons. (a) Transgenic nRKO mice were identified from tail DNA based on PCR amplication using primers for flox (700 bp) in upper panel, and CK2-Cre (300 bp) in the lower panel. Lane 1 indicates RAGE ${ }^{\text {floxfllox }}$ (non-Tg) mice with negative Cre transgene and lanes 2-3 denotes nRKO mice carried with both flox and Cre (RAGE floxflox/CK2-Cre). (b and c) Immunoblotting of cortical homogenates (b) and cerebellum (c) from the indicated Tg mice for RAGE. Tubulin was used as a protein-loading control. (d-f) Representative images of double immunostaining for RAGE and MAP2 in cortex (d and e) and hippocampus (f). Confocal microscopy images showing RAGE deletion in cortical neurons labeled with positive MAP2 as a neuronal marker. Enlarged large images of neurons derived from the corresponding cells are shown in the frame of panel (e). Scale bar $=50 \mu \mathrm{m}$

diabetes-associated complications. ${ }^{21,35}$ To verify whether $\mathrm{CML}$ was a major component in our AGE preparation, we prepared AGEs by incubation of bovine serum albumin (BSA) with glucose 6-phosphate for 6-8 weeks at $37^{\circ} \mathrm{C}$ and then performed immunochemical characterization using a monoclonal antibody targeting CML adducts. Using Coomassie blue dye for rapid reversible staining of protein bands in gel, we observed co-migration of BSA and AGE-modified BSA at $\sim 66$ and $\sim 70 \mathrm{kD}$, respectively (Figure $3 \mathrm{a}$ ). The increase in molecular weight of glycated BSA is due to AGE modification, which results in intramolecular crosslinking. Immunoblotting of the same preparation of BSA and AGE-BSA using specific antibody to $\mathrm{CML}$ showed prominent $\mathrm{CML}$ immunoreactivity only in the presence of AGEs, suggesting that BSA was glycated. In contrast, such immunoreactivity was absent on BSA without glucose 6-phosphate (Figure 3a). These results indicate that $\mathrm{CML}$ is a major component of our $\mathrm{AGE}$ preparation, used in all our experiments.

AGEs impair hippocampal long-term potentiation (LTP). To determine direct effect of AGEs on synaptic function, we examined synaptic transmission under basal condition and during LTP, a form of synaptic plasticity that is widely studied as a cellular model for synaptic function, in hippocampal slices from non-Tg mice treated with AGEs or BSA as a control. In vehicle-treated slices, BSA alone did not alter LTP $(228.8 \pm 17.04 \%$ versus $223.0 \pm 7.95 \%$ in BSA-treated slices, $P>0.05$, Figures $3 b$ and $c)$ or basal synaptic transmission (BST) as measured by input-output measurement (Figure 3d). AGE treatment significantly reduced LTP in a concentration-dependent manner $(180.9 \pm 15.36 \%, 139.1 \pm 10.42 \%$, and $124.9 \pm 7.96 \%$ for 50,100 , and $200 \mu \mathrm{g} / \mathrm{ml}$ AGEs, respectively, versus $220.9 \pm 20.75 \%$ for $100 \mu \mathrm{g} / \mathrm{ml}$ BSA, $P<0.01$, Figures $3 e$ and $\mathrm{f}$ ). There were no significant differences of fieldexcitatory post-synaptic potential (fEPSPs) in CA1 stratum radiatum between $A G E$ - and $B S A$-treated slices, indicating that AGEs did not affect normal BST in hippocampal synapses (Figure $3 \mathrm{~g}$ ). These results demonstrate that AGEs impair long-term synaptic plasticity.

RAGE deficiency rescues AGE-induced LTP deficits. To directly determine the impact of RAGE on AGE-mediated reduction of LTP, we first recorded LTP in hippocampal slices from global RAGE depletion (RKO) and non-Tg mice treated with AGEs. We found similar potentiation in RAGE-deficient 

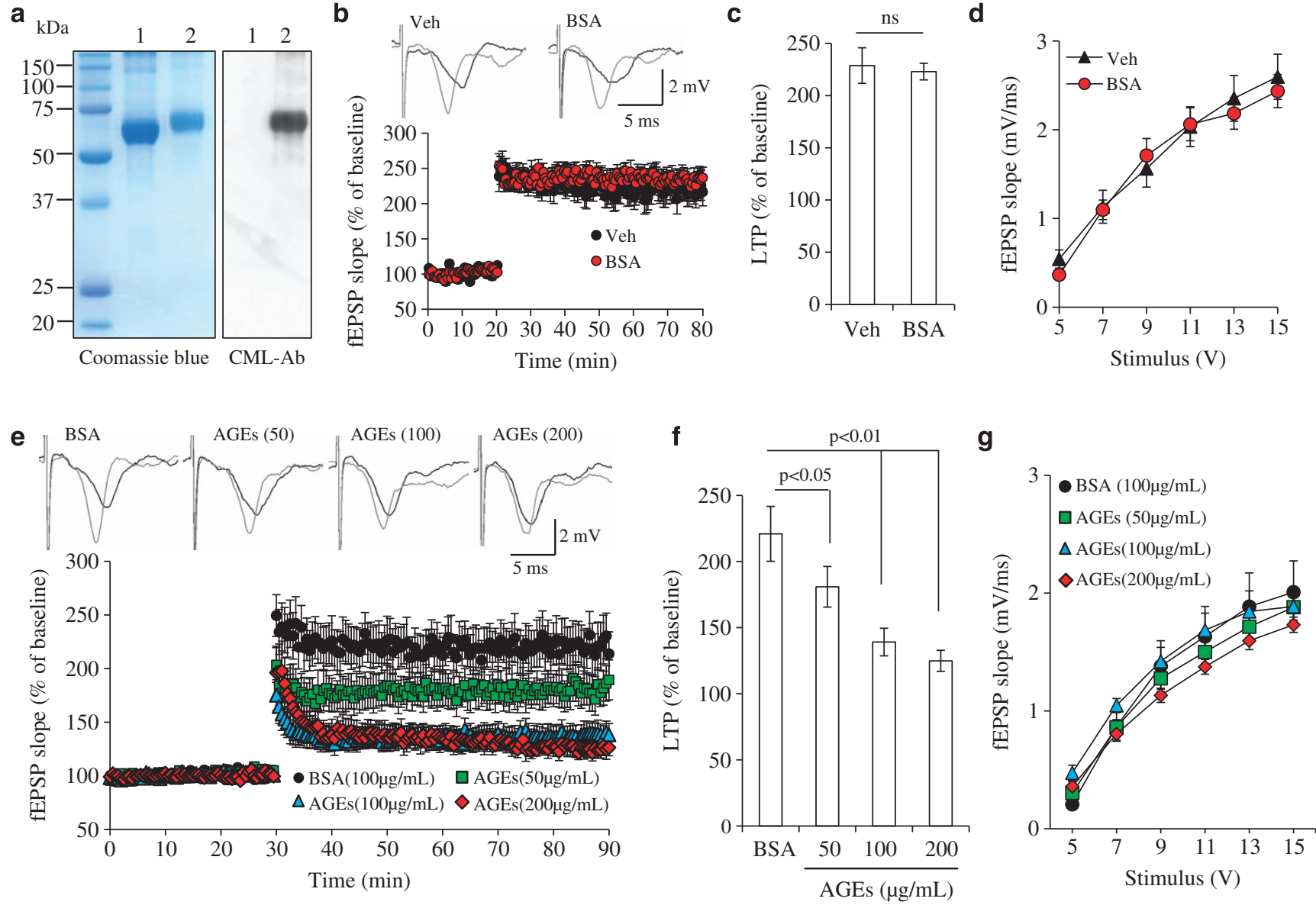

Figure 3 AGE-impaired long-term potentiation (LTP). (a) Determination of the degree of CML in AGE preparation. Protein (2 $\mu \mathrm{g})$ from BSA was incubated with glucose 6-phosphate for 8 weeks at $37^{\circ} \mathrm{C}$ and then subjected to SDS-PAGE. Protein bands were stained by Coomassie Blue (left). Glycation was detected by immunoblotting with antibody to CML (right). Lane 1, BSA; lane 2, AGE-modified BSA. (b) BSA alone did not affect LTP. Inserts show representative traces of fEPSP in slices treated with vehicle or $100 \mu \mathrm{g} / \mathrm{ml} \mathrm{BSA}$ before $\theta$-burst stimulation (black line) and at the end of $1 \mathrm{~h}$ recording (gray line). (c) Residual potentiation from the fEPSP slopes occurring over the last $5 \mathrm{~min}$ of LTP recordings. (d) BSA did not affect basal synaptic transmission (BST). (e) Effect of AGE on LTP. Hippocampal slices were perfused with AGE (50, 100, and 200 $\mu \mathrm{g} / \mathrm{ml}$ ) or BSA $(100 \mu \mathrm{g} / \mathrm{ml})$ for $1 \mathrm{~h}$ and then recorded LTP. $N=8-11$ slices from 3 to 5 mice. (f) Residual potentiation from the fEPSP slopes occurring over the last 5 min of LTP recordings. (g) The BST of hippocampal synapses was recorded from the indicated groups of mice

slices compared with non-Tg slices in the presence of BSA (224.3 $\pm 17.81 \%$ versus $208.8 \pm 19.50 \%, P>0.05$, Figures 4a and e). However, RAGE deficiency largely protected hippocampal slices against LTP decreases with AGEs exposure $(184.5 \pm 9.73 \%$ versus $131.1 \pm 7.53 \%, P<0.01$, Figures $4 a$ and $e)$, suggesting that RAGE deficiency improves synaptic transmission. Because RAGE is expressed in neuronal and non-neuronal cells in the brain, we next examined the contribution of neuronal RAGE to AGE-mediated synaptic function. We treated neurons from hippocampal slices from nRKO mice (with depletion of RAGE) cortices with AGEs and BSA for at least $60 \mathrm{~min}$, and then we recorded LTP. Slices from both $\mathrm{nRKO}$ or non-Tg mice showed similar LTP in the presence of BSA $(240.2 \pm 9.41 \%$ versus $208.8 \pm 19.50 \%, P>0.05$, Figures $4 \mathrm{~b}$ and $\mathrm{e})$. In contrast, nRKO slices significantly suppressed LTP decline induced by AGEs as compared with non-Tg slices $(191.6 \pm 15.55 \%$ versus $131.1 \pm 7.53 \%, \quad P<0.01$, Figures $4 \mathrm{~b}$ and e). These results indicate that successful blockade of neuronal RAGE protects from AGE-impaired synaptic function.
RAGE functions as a signal transduction receptor for AGEs and $A \beta$, activating multiple downstream intracellular pathways. ${ }^{27,28}$ Thus, we evaluated the effect of RAGE signaling in neurons on AGE-induced LTP using hippocampal slices from DN-RAGE mice expressing signal transduction-deficient mutants of RAGE (which were targeted to neurons to determine RAGE-dependent signaling). Notably, DN-RAGE slices were significantly resistant to AGE-mediated reduction of LTP as compared with non-Tg slices $(167.0 \pm 12.66 \%$ versus $131.1 \pm 7.53 \%, P<0.01$, Figures $4 \mathrm{c}$ and e). Figure $4 \mathrm{~d}$ shows representative traces taken $1 \mathrm{~min}$ before (black line) and $60 \mathrm{~min}$ after LTP induction (gray line). BST was not affected in RAGE knockout or mutant mice (Figure 4f). These results indicated that RAGEdependent signaling in neurons contributes to AGE-induced synaptic malfunction.

Mitogen-activated protein kinase 38 (MAPK p38) activation is involved in AGE-induced synaptic deficit. To determine which molecular players underlie AGE effects on hippocampal LTP, we evaluated the role of p38 and c-Jun 

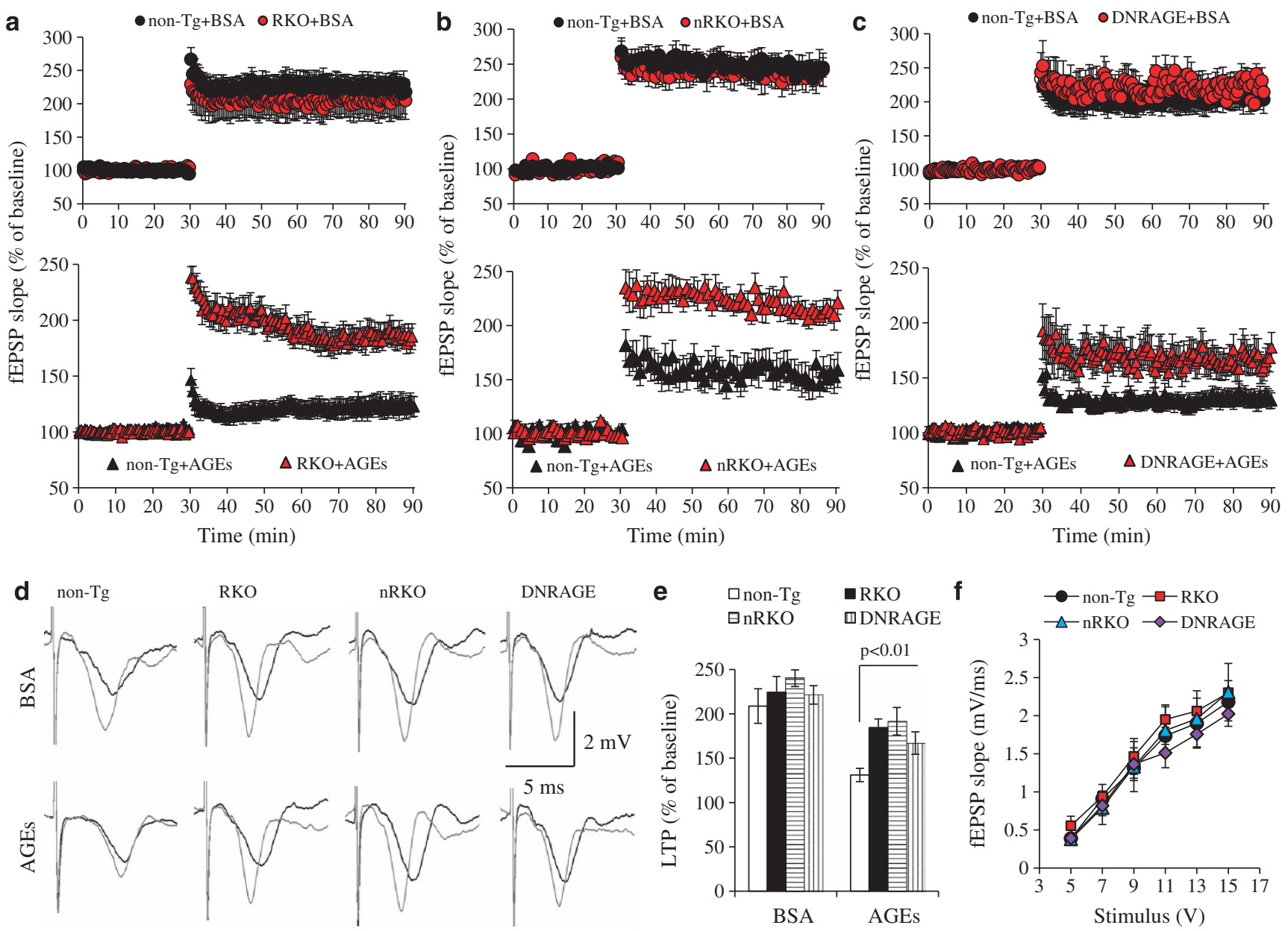

Figure 4 Effect of RAGE depletion on AGE-induced LTP impairment. (a-c) LTP was recorded in hippocampal slices from non-Tg, RKO (a), nRKO (b), and DN-RAGE (c) mice after $1 \mathrm{~h}$ perfusion with BSA or AGEs $(100 \mu \mathrm{g} / \mathrm{ml})$. RAGE deletion alone did not alter LTP in the presence of BSA. In contrast, LTP was increased in slices from RKO, nRKO, and DN-RAGE mice compared with non-Tg slices in the presence of AGE. (d) Representative traces of fEPSP in slices treated with vehicle or $100 \mu \mathrm{g} / \mathrm{ml} \mathrm{BSA}$ before $\theta$-burst stimulation (black line) and after $1 \mathrm{~h}$ (gray line). (e) Residual potentiation from the fEPSP slopes occurring over the last 5 min of LTP recordings. (f) There were no significant differences in BST among indicated groups. $N=8-11$ slices from 3 to 5 mice

$\mathrm{N}$-terminal kinases (JNK) in hippocampal slices upon exposure to AGEs, because these kinases are activated (increased phosphorylation levels) in several pathological conditions and synaptic plasticity; ${ }^{36,37}$ further, p38 is a key mediator of RAGE-mediated signal transduction. ${ }^{37}$ Using antibodies to phosphorylated forms of p38 and JNK with hippocampal extracts after exposure to AGEs and high frequency stimulation, we estimated activation of these two kinases. Addition of AGEs to non-Tg hippocampal slices significantly increased p38 phosphorylation compared with BSA addition, but treatment with AGEs did not affect total p38 levels (Figure 5a). Densitometry analysis of the combined immunoreactive bands revealed a significant increase in p38 phosphorylation by 1.5-1.7-fold when normalized to total p38 versus that of BSA-treated controls (Figure 5b). AGEs treatment did not affect JNK phosphorylation (Figure 5c).

To further evaluate the effect of p38 activation on AGE-mediated LTP impairment, we perfused hippocampal slides with SB203580, a specific p38 inhibitor, along with
AGEs. Clearly, SB203580 application significantly blocked induction of p38 phosphorylation in the presence of AGEs compared with the AGE treatment alone without p38 inhibitor (SB203580) (Figure 5d). Consequently, AGE-impaired hippocampal LTP was restored by inhibition of p38 with SB203580 perfusion (Figures $5 e$ and f). These results suggest that AGE-mediated p38 activation contributes to synaptic injury.

RAGE deficiency blocks AGE-induced p38 activation. To determine whether RAGE is a key player in AGEmediated p38 activation, we assessed the effect of RAGE deletion on p38 phosphorylation induced by AGEs. Slices from RKO mice showed completely suppressed p38 activation as shown by decreased p38 phosphorylation compared with non-Tg slices with AGEs (Figures 6a and b). Further, RAGE depletion specifically targeted to cortical/hippocampal neurons or neuron-targeted expression of a signal transduction-deficient mutant of RAGE abolished AGE-induced p38 phosphorylation. Quantification of all immunoreactive bands 
a

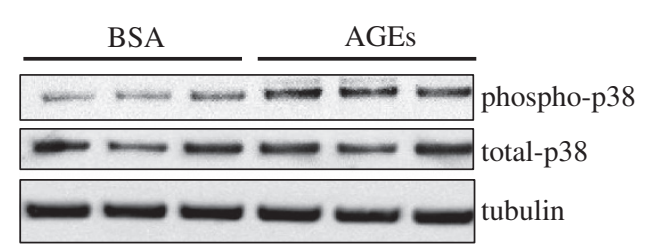

b

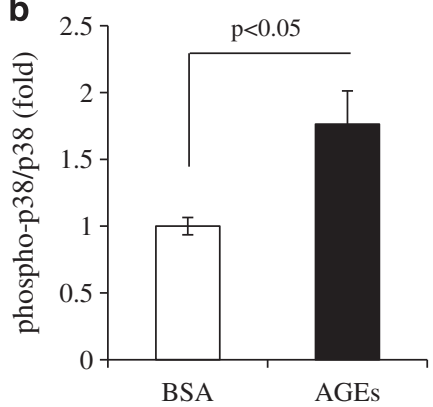

BSA

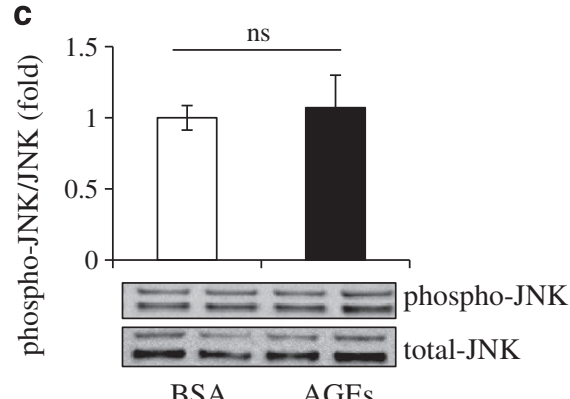

BSA AGEs

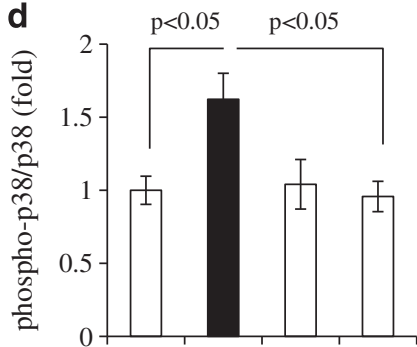

phospho-p38 $=$

total-p38

tubulin

AGEs:

SB203580: e
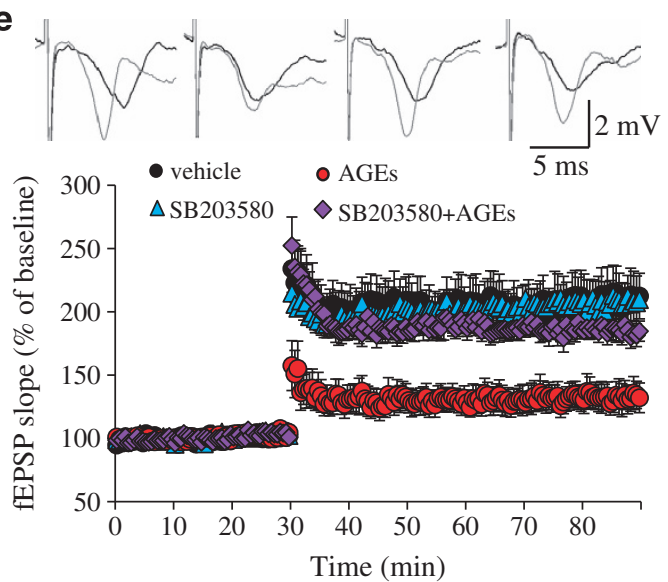

f

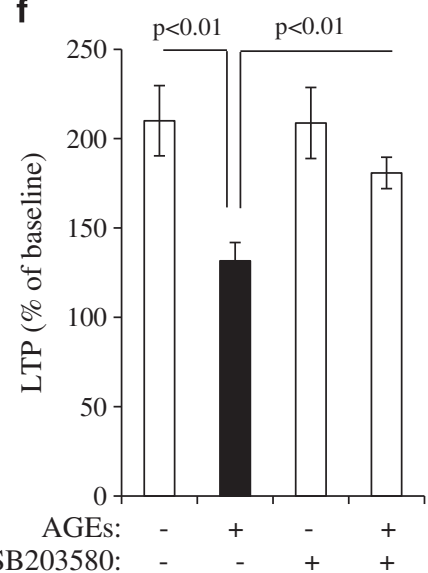

Figure 5 Effect of AGEs on p38 activation. Brain slices were perfused with BSA or AGEs (100 $\mu \mathrm{g} / \mathrm{ml})$ for $1 \mathrm{~h}$ and then subjected to immunoblotting for phosphorylation and total p38 (a and $\mathbf{b}$ ) or JNK (c). (a) Immunoblotting of brain homogenates from AGE- or BSA-treated slices for phosphorylation and total p38. Tubulin was used as the neuronal protein-loading control. (b) Densitometry of the combined phospho-p38 immunoreactive bands relative to total p38. (c) Densitometry of phospho-JNK immunoreactive bands relative to total JNK in slices treated with BSA or AGE. Data are expressed as fold increase relative to the BSA-treated control group. The lower panel shows representative immunoblots for the indicated proteins. $N=3-5$ per group of treatment. (d) Effect of p38 inhibitor (SB203580) on AGE-induced p38 phosphorylation. Densitometry of phospho-p38 immunoreactive bands relative to total p38 in non-Tg slices perfused with AGEs with or without SB203580. Representative immunoblots for the indicated protein are shown in the lower panel. (e) Effects of p38 inhibitor (SB203580) on AGE-induced LTP deficits in hippocampal slices. Slices were perfused with vehicle, AGEs (100 $\mu \mathrm{g} / \mathrm{ml}$ ), SB203580 $(1 \mu \mathrm{M})$, or AGEs plus SB203580 for $1 \mathrm{~h}$ before LTP recording. $n=8-11$ slices per group of treatment. Upper panel shows representative traces of fEPSP in slices with the indicated treatments before $\theta$-burst stimulation (black line) and at the end of $1 \mathrm{~h}$ (gray line). (f) Residual potentiation from fEPSP slopes occurring over the last 5 min of LTP recording

a

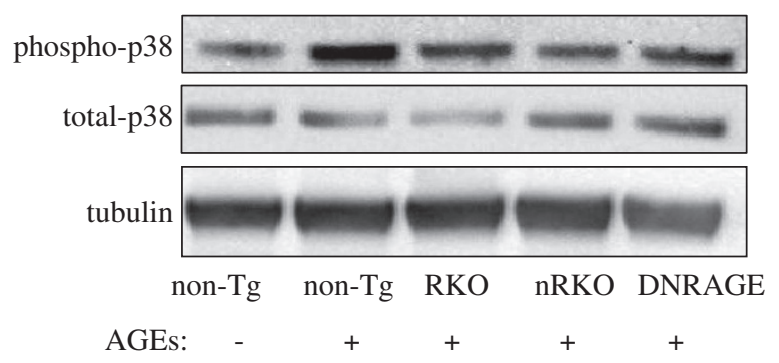

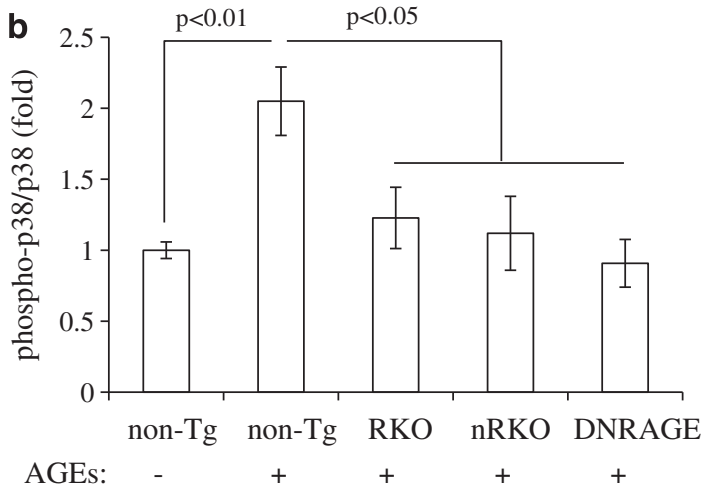

AGEs:

Figure 6 Effect of RAGE deficiency on AGE-induced p38 activation. Hippocampal slices from the indicated Tg mice and non-Tg mice were perfused with AGEs for $1 \mathrm{~h}$ and then subjected to immunoblotting for phospho- and total-p38. (a) Immunoblots for phospho- and total-p38 with tubulin used as protein-loading control. (b) Densitometry of phospho-p38 immunoreactive bands normalized by total p38 using the NIH Image $\mathrm{J}$ software. $N=3-5$ mice per group

for phospho-p38 normalized to total p38 verified significantly reduced phospho-p38 immunoreactive bands in slices from RKO, nRKO, and DN-RAGE compared with non-Tg slices with AGE treatment (Figures $6 a$ and b). These data indicate that RAGE deficiency prevents AGE-induced p38 activation. p38 activation of signal transduction is a consequence of AGEs-RAGE interaction on neurons, contributing to neuronal and synaptic perturbation in an AGE-enriched environment. 
Effect of AGEs-RAGE interaction on synaptic density. To determine the extent of AGE-induced synaptic damage in AGE-insulted neurons, we first analyzed the effect of AGEs on synaptic density. Synapses were identified as synaptophysin-positive clusters attaching to dendrites labeled with MAP2 marker. Recruitment of the presynaptic protein, synaptophysin, to form synaptophysin-positive clusters is rapid and synaptic activity-dependent. ${ }^{38}$ Two hours after AGEs treatment, synaptophysin density in hippocampal neurons was not altered compared with BSA-treated control cells, whereas hippocampal neurons exposed to AGEs for $48 \mathrm{~h}$ showed synaptophysin-positive cluster reduced by 50-60\% (Figure 7a). Importantly, RAGE-deficient neurons largely reversed AGE-induced decrease in synaptic density (Figure 7b). These data indicate that RAGE depletion rescues AGE-induced synaptic loss.

\section{Discussion}

In addition to its ability to directly alter the structure and function of targeted proteins within cells that causes cell or tissue damage, emerging evidence has also demonstrated AGEs as a signaling ligand, interacting with RAGE; AGEs elicit signal transduction changes that adversely affect numerous peripheral organs. ${ }^{39-41}$ Although AGE accumulation is increased in cortical neurons, hippocampal pyramidal neurons, astrocytes, and other glial cells in aging and $A D$ brain, ${ }^{4,42,43}$ the direct effect of AGEs-RAGE interaction on brain function, in particular on changes in synaptic structure and function, remains largely unknown. Using our novel transgenic mouse model with neuronal expression of RAGE signaling and lacking neuronal RAGE in the forebrain for evaluation of synaptic transmission and plasticity (almost every brain function relays on synaptic transmission), we provide convincing evidence to support a pivotal role of neuronal AGEs-RAGE interaction on MAPK P38 activation, hippocampal plasticity deficit, and synaptic injury.

We first demonstrated detrimental effect of AGEs on synaptic structure and function. The addition of AGEs significantly impaired synaptic plasticity by reducing LTP and synaptic morphology. LTP is important to long-term synaptic plasticity, and altered synaptic morphology (synaptic loss), which likely contributes to the learning and memory deficits seen in age-related cognitive decline. Aging is characterized by anatomical and functional decline across multiple organ systems. AGEs are found in the serum and accumulate in the tissue during aging; ${ }^{5,44,45}$ this accumulation is accelerated in pathological conditions such as diabetes and neurodegenerative diseases, including AD. Increased levels of AGEs are reported in the cortical neurons of older adults and are positively correlated with the severity of cognition impairment. ${ }^{46}$ The serum AGE levels were significantly increased in diabetic patients (equivalent to $30-88 \mu \mathrm{g} / \mathrm{ml}$ AGE-BSA versus $12 \mu \mathrm{g} / \mathrm{ml}$ AGE-BSA in non-diabetic patients). ${ }^{6-8}$ Our previous studies demonstrated that AGE albumin $(1 \mu \mathrm{M}$, equivalent to $66.5 \mu \mathrm{g} / \mathrm{ml}$ ) resulted in oxidant stress and activation of transcription factor NF-kB in vitro and in vivo, a process involving the AGE-binding protein RAGE. Notably, AGE-induced cellular perturbation and oxidant stress were blocked by antibodies to RAGE. ${ }^{47}$ Thus, increased levels of AGEs and of their receptor, RAGE, play an important role in AGE-mediated cellular perturbation during the pathogenesis of age-related processes and diabetes. The concentration of AGEs used in the present study correlates with that of the pathological condition found in human disease.

In our study, perfusion with AGEs in hippocampal slices impaired LTP in a concentration-dependent manner, consistent with findings observed in the rat model that exogenous a

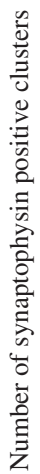

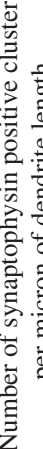

$\mathrm{p}<0.001$

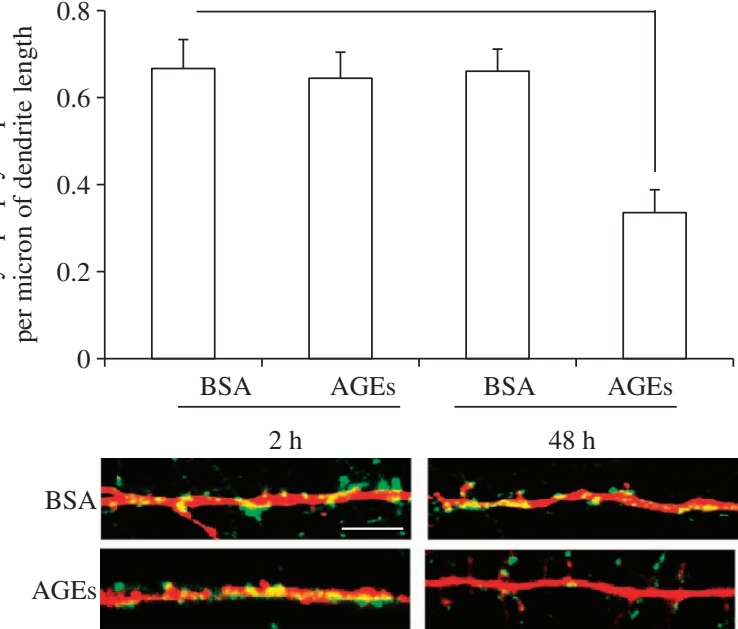

b

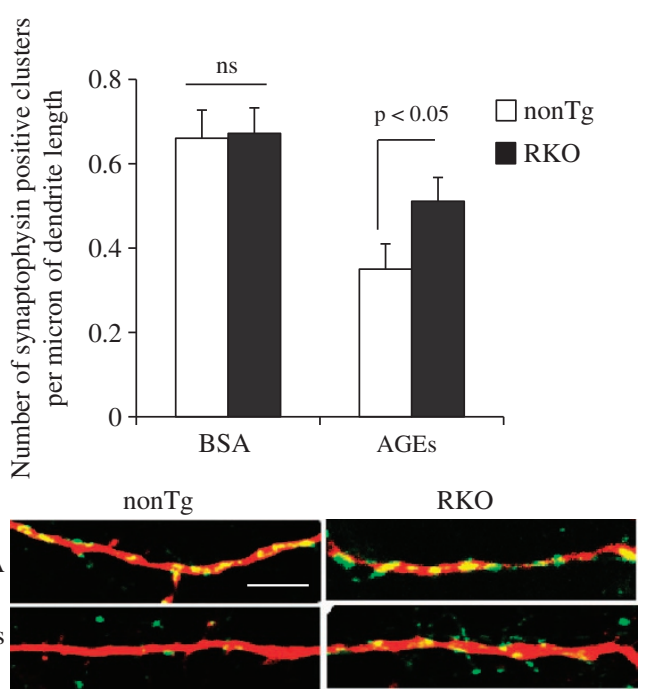

Figure 7 Effect of RAGE deficiency on AGE-induced synaptic loss. (a) Non-Tg neurons were treated with $100 \mu \mathrm{g} / \mathrm{ml} \mathrm{AGEs} \mathrm{or} \mathrm{BSA} \mathrm{for} 2$ and $48 \mathrm{~h}$ and then subjected to immunostaining with synaptophysin and MAP2. Quantification of positive synaptophysin clusters per micron of dendrites was significantly decreased in AGE-treated cells compared with BSA-treated cells. (b) RAGE-deficient neurons largely protected AGE-induced loss of synaptophysin-positive clusters compared with non-Tg neurons in the presence of AGEs. Lower panel shows representative images of synaptic staining. Synapses were visualized by synaptophysin staining (green) and dendrites by MAP2 staining (red). Scale bar $=50 \mu \mathrm{m}$ 
AGE treatment by stereotaxic injection into the brain led to synapse and memory impairments. ${ }^{48}$ However, the impact of neuronal RAGE on AGE-induced synaptic damage is unclear. Given that AGE formation and accumulation is accelerated in the brain of diabetic and AD subjects, AGEs-RAGE interaction could be an important target in the search for agents that halt disease acceleration or exacerbation relevant to diabetes- and AD-related cognitive decline and dementia.

Next, using our genetic RAGE depletion mouse model, we investigated the effect of RAGE-dependent signaling on AGE-insulted synaptic injury. AGE perfusion-induced LTP reduction may be caused by varying factors; for example, one cause involves AGE binding to RAGE receptors, and another is via protein crosslinking-induced cellular malfunction. Genetic deletion of RAGE offers us the ability to identify AGEs-RAGE interaction in AGE-induced synaptic impairment. We recorded normal LTP readings in brain slices of our global RAGE null mice treated with vehicle compared with non-transgenic littermates, indicating that genetic RAGE deletion does not significantly alter synaptic structures important for LTP induction and expression under normal physiological conditions. Notably, RAGE deficiency protects against AGE-induced LTP deficits. Similarly, our data demonstrate the protective effect of RAGE depletion on AGE-induced synaptic loss. Although our results did not exclude other effects of AGEs such as protein crosslinking, we clearly demonstrated that AGEs-RAGE interaction is involved in AGE-induced synaptic injury.

As RAGE is expressed in neurons and non-neuronal cells (i.e., glial, endothelial cells, and pericytes of the blood-brain barrier), ${ }^{49,50}$ the results obtained from global RAGE knockout mice do not delineate which cell type(s) is (are) important in AGE-induced synaptic plasticity impairment. Therefore, we created transgenic mice with $\mathrm{nRKO}$ and a signal transductiondeficient mutant of RAGE (DN-RAGE) specifically in the forebrain, including the hippocampus, to address the question of whether the activity of neuronal RAGE is responsible for AGE-induced hippocampal LTP reduction. Indeed, our findings clearly showed that $\mathrm{nRKO}$ and DN-RAGE brain slices were largely resistant to disruption of LTP via AGE exposure, implicating the involvement of neuronal RAGE in mechanisms underlying AGE-induced synaptic dysfunction. Further, introduction of neuronal DN-RAGE or RAGE deficiency in cortical neurons (nRKO) failed to completely prevent AGE-impaired LTP compared with perfusion with BSA. These results suggest that non-neuronal RAGE (i.e., RAGE expression in microglia, astrocyte, or endothelial cells) may be involved in AGE-induced synaptic dysfunction. Future studies will be required to investigate the role of non-neuronal RAGE in synaptic failure induced by AGEs. Regardless, our studies delineate the mechanisms involving neuronal RAGE-mediated signal transduction in AGEinduced synaptic dysfunction and degeneration. Neurons are susceptible to AGE insults via direct AGEs-RAGE interaction contributing to synaptic dysfunction and degeneration.

Finally, our results suggest that the MAPK P38 signaling pathway is critical for AGEs-RAGE-induced synaptic damage. AGE-induced LTP decline was attenuated in DN-RAGE slices with a signal transduction-deficient mutant of RAGE, indicating the contribution of RAGE-dependent signaling to AGE-induced synaptic impairment. Signaling cascades activated after ligand-RAGE interaction include pathways those of p21ras, extracellular signal-regulated kinase 1/2 (ERK1/2), p38, and JNK, Rho GTPases, phosphoinositol-3 kinase, GSK-3 $\beta$, and the JAK/STAT (signal transducer and activator of transcription). ${ }^{51,52}$ Activation of different protein kinase cascades may represent a principal target of RAGE activation for control of synaptic plasticity. ${ }^{37,53}$

In particular, we considered the potential involvement of two different kinases, JNK and p38 in LTP inhibition based on our previous study showing that p38 and JNK activation are required for LTP inhibition induced by $A \beta-$ RAGE interaction. $^{37,54}$ Hippocampal slices perfused with AGEs showed increased p38 activity but no change in JNK, suggesting the involvement of p38 activation in p38 signaling and the AGE-induced synaptic plasticity deficits. Indeed, the addition of p38 inhibitor prevented AGE-induced p38 activation and LTP impairment. Note, RAGE depletion blocked induction of p38 phosphorylation and restored defects in synaptic plasticity and density from AGE exposure. Our results indicate that neuronal AGEs-RAGE interaction activates p38 MAK kinase, which in turn leads to synaptic dysfunction.

We further observed that if AGEs level remained chronically high, synapses become structurally damaged. Using hippocampal neuronal cultures, we showed that short-term AGEs exposure (for $2 \mathrm{~h}$ treatment) barely affected synaptic structure, whereas long-term treatment of AGEs (for $48 \mathrm{~h}$ ) caused significant changes in synaptic density. Importantly, RAGE deletion rescues AGE-induced synapse loss. These data indicate that neuronal AGEs-RAGE interaction has functional (long-term plasticity) as well as structural effects on synapses, which may be important in the learning and memory deficit present in age-related dementia and age-associated neurodegenerative disease.

In summary, we provide substantial evidence of the protective effect of RAGE depletion on AGE-induced alterations in synaptic plasticity and density. Genetic depletion of RAGE and RAGE signaling in cortical neurons blocks AGEmediated activation of p38 MAP kinase signal transduction with LTP deficits. We propose that AGEs-RAGE-dependent activation of p38 MAP kinase is responsible for AGE-induced synaptic damage. Blockade of AGEs-RAGE axis may protect against the impaired cognitive function in aged subjects with and without neurodegenerative diseases, including those with diabetes and $A D$.

\section{Materials and Methods \\ Transgenic mice}

Generation and characterization of conditional neuronal knockout of RAGE mice

Targeted disruption of mouse RAGE gene. We used the Cre-loxP system to generate the targeting vector and the RAGE/flox mice (performed by Ozgen Inc.). The targeting vector consists of three fragments, namely, the $5^{\prime}$ homology arm, $3^{\prime}$ homology arm, and loxP arm. Two loxP sites flank RAGE exons 2-4 to allow for Cre-mediated deletion using Cre recombinase. Excision of exons 2-4 by Cre recombinase led to a frame shift and early stop codon from the mouse RAGE sequence. A PGK-neo selection cassette was inserted downstream of exon 1. The PGK-neomycin resistance selection cassette is flanked by FRT sites and was deleted using FLPe recombinase (Figure 1, targeting vector). 
Generation of neuronal deletion of RAGE mice (nRKO). After deletion of the PKGneo cassette by crossing with FlpE-deletor C57BL/6 mice (Ozgen Inc.) to eliminate the neomycin resistance selection cassette (PKG-neo), the floxed RAGE allele was generated. To generate Cre recombinase RAGE null mice (RAGE ${ }^{\text {floxflox }} / C K 2$ Cre, namely, nRKO mice), selective for the cortical and hippocampal neuron under the control of the Camk2a (CK2) promoter, RAGE/flox mice were bred with neuronal-targeted and region-restricted transgenic mice that express Cre recombinase in the entire forebrain (L7Ag13 line) under the control of the forebrain-specific CAMK II promoter. $^{34}$ Cre mice (L7Ag13 line) were kindly provided by Dr. Eric Kandel (Columbia University, New York, NY, USA). Floxed RAGE mice were identified by PCR with primers (forward: $5^{\prime}$-TACCGAGTCC GAGTCTACCGTAAG- $3^{\prime}$ and reverse: $5^{\prime}$-TCTCCTGGTCTCTTCCTTCACGAG- ${ }^{\prime}$ ) to amplify a 551-bp fragment from the wild-type (WT) allele and a 700-bp fragment from the flox $\triangle$ neo allele. The Cre transgene was identified by PCR primers (forward: $5^{\prime}$-CTTCATCGTCGGTCCG-3' and reverse: $5^{\prime}$-ACATTCTCCCACCGTC- $3^{\prime}$ ) to amplify a 300-bp fragment. Specific neuronal RAGE knockout was further confirmed by western blotting of cortical and cerebellum homogenates using rabbit anti-RAGE antibody (generated in our Lab and used in our previous study ${ }^{55}$ ). All transgenic mice were of the C57BL/6 strain. The Institutional Animal Care and Use Committee of the University of Kansas approved all protocols. Male transgenic mice and their littermate controls were used for the in vitro electrophysiology experiments.

Homozygous RAGE-null mice (RKO) and transgenic mice with cytosolic dominant-negative RAGE (DN-RAGE)

We generated and characterized homozygous RAGE-null mice (RKO) as described previously. ${ }^{33,56}$ In addition, we used transgenic mice with signal transduction-deficient mutants of RAGE in which the cytosolic domain of the receptor was deleted, thereby imparting a dominant-negative (DN)-RAGE effect, targeted to neurons (DN-RAGE) driven by the platelet-derived growth factor-B chain promoter. DN-RAGE mice were previously characterized, demonstrating localization of DN-RAGE in cortical neurons. ${ }^{54}$

\section{Preparation of AGEs}

We generated AGEs by incubating BSA $(25 \mathrm{mg} / \mathrm{ml})$ with $250 \mathrm{mM}$ glucose 6-phosphate at $37^{\circ} \mathrm{C}$ for $6-8$ weeks in $0.1 \mathrm{M}$ phosphate buffer containing $1.5 \mathrm{mM}$ PMSF, $0.5 \mathrm{mM}$ EDTA, and $1 \mathrm{mM}$ azide. ${ }^{57}$ The control preparation (BSA) was treated identically with the exception that glucose 6-phosphate was omitted. We dialyzed preparations with phosphate buffer to remove free glucose, EDTA, PMSF, and azide after incubation. The degree of glycation was determined by immunoblotting using antibody to CML (TransGenic Inc., Kobe, Japan). Coomassie blue staining of gel was used as a protein-loading control.

\section{Electrophysiological studies}

Electrophysiological studies were performed as described. ${ }^{54,58}$ Transverse hippocampal slices $(400 \mu \mathrm{m})$ were cut from the mouse brain, maintained in an interface chamber at $29^{\circ} \mathrm{C}$, and perfused with artificial cerebrospinal fluid (aCSF) continuously bubbled with $95 \% \mathrm{O} 2$ and $5 \% \mathrm{CO}$. The aCSF composition (in $\mathrm{mM}$ ) was: $124.0 \mathrm{NaCl}, 4.4 \mathrm{KCl}, 1.0 \mathrm{Na}_{2} \mathrm{HPO}_{4}, 25.0 \mathrm{NaHCO}_{3}, 2.0 \mathrm{CaCl}_{2}, 2.0 \mathrm{MgCl}_{2}$, and 10.0 glucose. fEPSP was recorded for the CA1 region of the hippocampus by placing the stimulating electrode at the level of the Schaeffer collateral fibers and recording electrode in the CA1 stratum radiatum. BST was assayed by plotting the stimulus voltage $(V$ against slopes of fEPSP to generate input-output relations. For LTP experiments, a test pulse was applied every minute at an intensity evoking $\sim 35 \%$ of the maximum evoked response. LTP was induced using $\theta$-burst stimulation (4 pulses at $100 \mathrm{~Hz}$, with bursts repeated at $5 \mathrm{~Hz}$ and each tetanus, including three 10-burst trains separated by $15 \mathrm{~s}$ ). Responses were recorded for $60 \mathrm{~min}$ after tetanization and measured as fEPSP slope expressed as the percentage of baseline.

\section{Immunoblotting analysis}

Brain slices were lysed in extraction buffer $(10 \mathrm{mM}$ Tris- $\mathrm{HCl}(\mathrm{pH}$ 7.4), $100 \mathrm{mM}$ sodium chloride, $1 \mathrm{mM}$ EDTA, $1 \mathrm{mM}$ EGTA, $1 \mathrm{mM}$ sodium fluoride, $20 \mathrm{mM}$ sodium pyrophosphate, $2 \mathrm{mM}$ sodium orthovanadate, $1 \%$ Triton X-100, $10 \%$ glycerol, $0.1 \%$ SDS, $0.5 \%$ deoxycholate, $1 \mathrm{mM}$ PMSF) containing protease inhibitor mixture (set V, EDTA-free; Calbiochem, Billerica, MA, USA). Protein extracts were separated by SDS/PAGE (12\% Bis-Tris gel; Invitrogen, Grand Island, NY, USA), and then transferred to a nitrocellulose membrane (Amersham, Pittsburgh, PA, USA).
After blocking in TBST buffer $(20 \mathrm{mM}$ Tris- $\mathrm{HCl}, 150 \mathrm{mM}$ sodium chloride, $0.1 \%$ Tween-20) containing $5 \%$ non-fat dry milk (Santa Cruz, Dallas, TX, USA) for $1 \mathrm{~h}$ at room temperature, we incubated the membrane, and gently shaking overnight (at $4{ }^{\circ} \mathrm{C}$ ) with primary antibodies, followed by incubation with the corresponding secondary antibody for $1 \mathrm{~h}$ at room temperature. We used antibodies to phosphorylation and total of p38 and JNK (Cell Signaling, Boston, MA, USA) and tubulin (Sigma, St. Louis, MO, USA). ImageJ software (National Institutes of Health, Bethesda, MD, USA) was used for analysis of scanned blots and to quantify intensity of the immunoreactive bands.

\section{Immunohistochemical analysis}

Mice were anesthetized by an intraperitoneal injection of a mixture of ketamine $(50 \mathrm{mg} / \mathrm{kg})$ and xylazine $(10 \mathrm{mg} / \mathrm{kg})$ and perfused transcardially with $0.9 \%$ sodium chloride for $10 \mathrm{~min}$. Mouse brains were fixed in $4 \%$ paraformaldehyde at $4{ }^{\circ} \mathrm{C}$ for 2 days. Floating coronal sections of 30- $\mu \mathrm{m}$ thicknesses were cut by vibratome (Leica VT 1000S, Wetzlar, Germany), collected, and immersed in wash buffer $(0.1 \mathrm{M}$ sodium phosphate, $0.5 \mathrm{M}$ sodium chloride, Triton X-100, pH 7.4) for 30 min. After preincubation for $1 \mathrm{~h}$ in blocking solution (10\% normal goat serum, $0.3 \%$ Triton $\mathrm{X}-100$ in PBS), we incubated sections overnight at $4{ }^{\circ} \mathrm{C}$ with primary antibodies, using rabbit anti-RAGE $\mathrm{lgG}(3.5 \mu \mathrm{g} / \mathrm{ml}$, generated in our Lab) and mouse antiMAP2 (1:10000, Chemicon, Billerica, MA, USA) for cortex and hippocampus staining. Sections were then incubated with Alexa Fluor 594-conjugated goat antirabbit IgG and 488 goat anti-mouse IgG secondary antibodies (1:1000, Invitrogen) for $1 \mathrm{~h}$ at room temperature. Nuclei were stained by DRAQ5 $(5 \mu \mathrm{M}$, Cell Signaling) for $5 \mathrm{~min}$ at room temperature.

\section{Measurement of synaptic density}

Neuronal culture. We prepared hippocampal neurons from day 1 non-Tg or RKO mice in the C57/BL6 background as described previously, ${ }^{59}$ culturing neurons in neurobasal medium supplemented with 1 X B27, $600 \mu \mathrm{M}$ L-Glutamine and penicillin-streptomycin. At day 10 in vitro, neurons from both $\mathrm{Tg}$ mice were treated with $100 \mu \mathrm{g} / \mathrm{ml}$ of AGEs; BSA was used as a control in neurobasal medium supplemented with $0.5 \mathrm{X} \mathrm{B27}$ for 2 and $48 \mathrm{~h}$, respectively.

Immunostaining of cultured neurons. After the various treatments, neurons were fixed with $4 \%$ ice-cold paraformaldehyde for $5 \mathrm{~min}$ and then permeabilized with PBS containing $0.1 \%$ Triton and $5 \%$ goat serum for $1 \mathrm{~h}$ at room temperature followed by incubation with primary antibodies (rabbit anti-synaptophysin IgG (1:5000, Dako) and mouse anti-MAP2 IgG (1:10000, Chemicon)) to visualize dendrites at $4{ }^{\circ} \mathrm{C}$ for $16 \mathrm{~h}$. Neurons were incubated with both Alexa Fluor 488-conjugated goat anti-rabbit IgG and 594 goat anti-mouse IgG (1:1000, Invitrogen) for $1 \mathrm{~h}$ at room temperature. After washing with PBS, neurons were covered with Vectashield mounting medium $(\mathrm{H}-1000$, Vector Laboratories, Burlingame, CA, USA). Images were taken at equal exposure for all the different groups at $\times 63$ oil lens under a confocal microscopy (Leica) and analyzed by the Universal Metamorp Image Program (Molecular Devices, Sunnyvale, CA, USA).

Synaptic density of cultured neurons was measured by counting the number of synaptophysin-positive clusters in secondary branches and puncta per micron of dendrite (presented as the number of synaptophysin clusters per micron of dendrite) and calculated by dividing the length of the dendrite. The experiments were performed by investigators blinded to the information about genotype and treatment. Codes for the ID of group cells were not disclosed until completion of image analysis.

\section{Statistical analysis}

One-way ANOVA was used for repeated measure analyses followed by Fisher's protected least significant difference for post hoc comparisons. We used StatView 5.0.1 Windows software (SAS Institute, Cary, NC, USA), and results are reported as mean \pm S.E.M. $P<0.05$ was considered significant.

\section{Conflict of Interest}

The authors declare no conflict of interest.

Acknowledgements. This work was supported by the National Institute of Aging (R37AG037319) and the National Institute of Neurological Disorders and Stroke (R01NS65482). 
1. Li J, Liu D, Sun L, Lu Y, Zhang Z. Advanced glycation end products and neurodegenerative diseases: mechanisms and perspective. J Neurol Sci 2012; 317: 1-5.

2. Munch G, Thome J, Foley P, Schinzel R, Riederer P. Advanced glycation endproducts in ageing and Alzheimer's disease. Brain Res Brain Res Rev 1997; 23: 134-143.

3. Vlassara H, Striker GE. Advanced glycation endproducts in diabetes and diabetic complications. Endocrinol Metab Clin North Am 2013; 42: 697-719.

4. Takedo A, Yasuda T, Miyata T, Mizuno K, Li M, Yoneyama S et al. Immunohistochemical study of advanced glycation end products in aging and Alzheimer's disease brain. Neurosci Lett 1996; 221: 17-20.

5. Luth HJ, Ogunlade V, Kuhla B, Kientsch-Engel R, Stahl P, Webster J et al. Age- and stage-dependent accumulation of advanced glycation end products in intracellular deposits in normal and Alzheimer's disease brains. Cereb Cortex 2005; 15: 211-220.

6. Ono Y, Aoki S, Ohnishi K, Yasuda T, Kawano K, Tsukada Y. Increased serum levels of advanced glycation end-products and diabetic complications. Diabetes Res Clin Pract 1998; 41: 131-137.

7. Shimoike T, Inoguchi T, Umeda F, Nawata H, Kawano K, Ochi H. The meaning of serum levels of advanced glycosylation end products in diabetic nephropathy. Metabolism 2000; 49: $1030-1035$

8. Chaturvedi N, Schalkwijk CG, Abrahamian H, Fuller JH, Stehouwer CD. Group EPCS. Circulating and urinary transforming growth factor beta1, Amadori albumin, and complications of type 1 diabetes: the EURODIAB prospective complications study. Diabetes Care 2002; 25: 2320-2327.

9. Guglielmotto M, Aragno M, Tamagno E, Vercellinatto I, Visentin S, Medana C et al. AGEs/ RAGE complex upregulates BACE1 via NF-kappaB pathway activation. Neurobiol Aging 2012; 331: e113-e127.

10. Yaffe K, Lindquist K, Schwartz AV, Vitartas C, Vittinghoff E, Satterfield S et al. Advanced glycation end product level, diabetes, and accelerated cognitive aging. Neurology 2011; 77: 1351-1356.

11. Ott A, Stolk RP, van Harskamp F, Pols HA, Hofman A, Breteler MM. Diabetes mellitus and the risk of dementia: the Rotterdam Study. Neurology 1999; 53: 1937-1942.

12. Skoog I, Lernfelt B, Landahl S, Palmertz B, Andreasson LA, Nilsson L et al. 15-year longitudinal study of blood pressure and dementia. Lancet 1996; 347: $1141-1145$.

13. Leibson CL, O'Brien PC, Atkinson E, Palumbo PJ, Melton LJ 3rd. Relative contributions of incidence and survival to increasing prevalence of adult-onset diabetes mellitus: a population-based study. Am J Epidemiol 1997; 146: 12-22.

14. Stolk RP, Breteler MM, Ott A, Pols HA, Lamberts SW, Grobbee DE et al. Insulin and cognitive function in an elderly population. The Rotterdam Study. Diabetes Care 1997; 20: 792-795.

15. Kilander L, Nyman $H$, Boberg M, Hansson L, Lithell $H$. Hypertension is related to cognitive impairment: a 20-year follow-up of 999 men. Hypertension 1998; 31 : 780-786.

16. Grant WB. Dietary links to Alzheimer's disease: 1999 update. J Alzheimers Dis 1999; 1: 197-201.

17. Myers A, Holmans $P$, Marshall $H$, Kwon J, Meyer D, Ramic $D$ et al. Susceptibility locus for Alzheimer's disease on chromosome 10. Science 2000; 290: 2304-2305.

18. Petot GJ, Traore F, Debanne SM, Lerner AJ, Smyth KA, Friedland RP. Interactions of apolipoprotein $\mathrm{E}$ genotype and dietary fat intake of healthy older persons during mid-adult life. Metabolism 2003; 52: 279-281.

19. Vitek MP, Bhattacharya K, Glendening JM, Stopa E, Vlassara H, Bucala R et al. Advanced glycation end products contribute to amyloidosis in Alzheimer disease. Proc Natl Acad Sci USA 1994; 91: 4766-4770.

20. Yan SD, Chen X, Schmidt AM, Brett J, Godman G, Zou YS et al. Glycated tau protein in Alzheimer disease: a mechanism for induction of oxidant stress. Proc Natl Acad Sci USA 1994; 91: 7787-7791.

21. Yan SD, Yan SF, Chen X, Fu J, Chen M, Kuppusamy P et al. Non-enzymatically glycated tau in Alzheimer's disease induces neuronal oxidant stress resulting in cytokine gene expression and release of amyloid beta-peptide. Nat Med 1995; 1: 693-699.

22. Loske C, Gerdemann A, Schepl W, Wycislo M, Schinzel R, Palm D et al. Transition metal-mediated glycoxidation accelerates cross-linking of beta-amyloid peptide. Eur J Biochem 2000; 267: 4171-4178.

23. Li XH, Xie JZ, Jiang X, Lv BL, Cheng XS, Du LL et al. Methylglyoxal induces tau hyperphosphorylation via promoting AGEs formation. Neuromolecular Med 2012; 14 : 338-348.

24. Ledesma MD, Bonay P, Colaco C, Avila J. Analysis of microtubule-associated protein tau glycation in paired helical filaments. J Biol Chem 1994; 269: 21614-21619.

25. Necula M, Kuret J. Pseudophosphorylation and glycation of tau protein enhance but do not trigger fibrillization in vitro. J Biol Chem 2004; 279: 49694-49703.

26. Grillo MA, Colombatto S. Advanced glycation end-products (AGEs): involvement in aging and in neurodegenerative diseases. Amino Acids 2008; 35: 29-36.

27. Neeper M, Schmidt AM, Brett J, Yan SD, Wang F, Pan YC et al. Cloning and expression of a cell surface receptor for advanced glycosylation end products of proteins. J Biol Chem 1992; 267: 14998-15004

28. Schmidt AM, Vianna M, Gerlach M, Brett J, Ryan J, Kao J et al. Isolation and characterization of two binding proteins for advanced glycosylation end products from bovine lung which are present on the endothelial cell surface. J Biol Chem 1992; 267: 14987-14997.

29. Yan SS, Chen D, Yan S, Guo L, Du H, Chen JX. RAGE is a key cellular target for Abeta-induced perturbation in Alzheimer's disease. Front Biosci (Schol Ed) 2012; 4: 240-250.

30. Schmidt AM, Hasu M, Popov D, Zhang JH, Chen J, Yan SD et al. Receptor for advanced glycation end products (AGEs) has a central role in vessel wall interactions and gene activation in response to circulating AGE proteins. Proc Natl Acad Sci USA 1994; 91 : 8807-8811.

31. Schmidt AM, Hori O, Chen JX, Li JF, Crandall J, Zhang J et al. Advanced glycation endproducts interacting with their endothelial receptor induce expression of vascular cell adhesion molecule-1 (VCAM-1) in cultured human endothelial cells and in mice. A potential mechanism for the accelerated vasculopathy of diabetes. J Clin Invest 1995; 96: 1395-1403.

32. Vlassara H. The AGE-receptor in the pathogenesis of diabetic complications. Diabetes Metab Res Rev 2001; 17: 436-443.

33. Sakaguchi T, Yan SF, Yan SD, Belov D, Rong LL, Sousa M et al. Central role of RAGE-dependent neointimal expansion in arterial restenosis. J Clin Invest 2003; 111: 959-972.

34. Zakharenko SS, Patterson SL, Dragatsis I, Zeitlin SO, Siegelbaum SA, Kandel ER et al. Presynaptic BDNF required for a presynaptic but not postsynaptic component of LTP at hippocampal CA1-CA3 synapses. Neuron 2003; 39: 975-990.

35. Reddy S, Bichler J, Wells-Knecht KJ, Thorpe SR, Baynes JW. N epsilon-(carboxymethyl)lysine is a dominant advanced glycation end product (AGE) antigen in tissue proteins. Biochemistry 1995; 34: 10872-10878.

36. Origlia N, Arancio O, Domenici L, Yan SS. MAPK beta-amyloid and synaptic dysfunction: the role of RAGE. Expert Rev Neurother 2009; 9: 1635-1645.

37. Origlia N, Righi M, Capsoni S, Cattaneo A, Fang F, Stern DM et al. Receptor for advanced glycation end product-dependent activation of p38 mitogen-activated protein kinase contributes to amyloid-beta-mediated cortical synaptic dysfunction. J Neurosci 2008; 28: 3521-3530.

38. Jin I, Udo H, Hawkins RD. Rapid increase in clusters of synaptophysin at onset of homosynaptic potentiation in Aplysia. Proc Natl Acad Sci USA 2011; 108: 11656-11661.

39. Schmidt AM, Yan SD, Yan SF, Stern DM. The biology of the receptor for advanced glycation end products and its ligands. Biochim Biophys Acta 2000; 1498: 99-111.

40. Bucciarelli LG, Wendt T, Rong L, Lalla E, Hofmann MA, Goova MT et al. RAGE is a multiligand receptor of the immunoglobulin superfamily: implications for homeostasis and chronic disease. Cell Mol Life Sci 2002; 59: 1117-1128.

41. Bierhaus A, Humpert PM, Morcos M, Wendt T, Chavakis T, Arnold B et al. Understanding RAGE, the receptor for advanced glycation end products. $J \mathrm{Mol}$ Med (Berl) 2005; 83: 876-886.

42. Kimura T, Takamatsu J, Ikeda K, Kondo A, Miyakawa T, Horiuchi S. Accumulation of advanced glycation end products of the Maillard reaction with age in human hippocampal neurons. Neurosci Lett 1996; 208: 53-56.

43. Horie K, Miyata T, Yasuda T, Takeda A, Yasuda Y, Maeda K et al. Immunohistochemical localization of advanced glycation end products, pentosidine, and carboxymethyllysine in lipofuscin pigments of Alzheimer's disease and aged neurons. Biochem Biophys Res Commun 1997; 236: 327-332.

44. Uribarri J, Cai W, Peppa M, Goodman S, Ferrucci L, Striker G et al. Circulating glycotoxins and dietary advanced glycation endproducts: two links to inflammatory response, oxidative stress, and aging. J Gerontol A Biol Sci Med Sci 2007; 62: $427-433$.

45. Thangthaeng N, Sumien N, Forster MJ. Dissociation of functional status from accrual of CML and RAGE in the aged mouse brain. Exp Gerontol 2008; 43: 1077-1085.

46. Southern L, Williams J, Esiri MM. Immunohistochemical study of N-epsilon-carboxymethyl lysine (CML) in human brain: relation to vascular dementia. BMC Neurol 2007; 7: 35.

47. Yan SD, Schmidt AM, Anderson GM, Zhang J, Brett J, Zou YS et al. Enhanced cellular oxidant stress by the interaction of advanced glycation end products with their receptors/ binding proteins. J Biol Chem 1994; 269: 9889-9897.

48. Li XH, Lv BL, Xie JZ, Liu J, Zhou XW, Wang JZ. AGEs induce Alzheimer-like tau pathology and memory deficit via RAGE-mediated GSK-3 activation. Neurobiol Aging 2012; 33: 1400-1410.

49. Schmidt AM, Yan SD, Yan SF, Stern DM. The multiligand receptor RAGE as a progression factor amplifying immune and inflammatory responses. J Clin Invest 2001; 108: 949-955.

50. Lue LF, Yan SD, Stern DM, Walker DG. Preventing activation of receptor for advanced glycation endproducts in Alzheimer's disease. Curr Drug Targets CNS Neurol Disord 2005; 4: 249-266.

51. Lin L, Park S, Lakatta EG. RAGE signaling in inflammation and arterial aging. Front Biosci (Landmark Ed) 2009; 14: 1403-1413.

52. Vazzana N, Santilli F, Cuccurullo C, Davi G. Soluble forms of RAGE in internal medicine. Intern Emerg Med 2009; 4: 389-401.

53. Origlia N, Bonadonna C, Rosellini A, Leznik E, Arancio O, Yan SS et al. Microglial receptor for advanced glycation end product-dependent signal pathway drives 
beta-amyloid-induced synaptic depression and long-term depression impairment in entorhinal cortex. J Neurosci 2010; 30: 11414-11425.

54. Arancio O, Zhang HP, Chen X, Lin C, Trinchese F, Puzzo D et al. RAGE potentiates Abeta-induced perturbation of neuronal function in transgenic mice. EMBO J 2004; 23 4096-4105.

55. Fang F, Lue LF, Yan S, Xu H, Luddy JS, Chen D et al. RAGE-dependent signaling in microglia contributes to neuroinflammation, Abeta accumulation, and impaired learning/ memory in a mouse model of Alzheimer's disease. FASEB J 2010; 24: 1043-1055.

56. Takuma K, Fang F, Zhang W, Yan S, Fukuzaki E, Du H et al. RAGE-mediated signaling contributes to intraneuronal transport of amyloid-beta and neuronal dysfunction. Proc Nat Acad Sci USA 2009; 106: 20021-20026.

57. Chang CT, Wu MS, Tian YC, Chen KH, Yu CC, Liao CH et al. Enhancement of epithelial sodium channel expression in renal cortical collecting ducts cells by advanced glycation end products. Nephrol Dial Transplant 2007; 22: 722-731.

58. Du H, Guo L, Fang F, Chen D, Sosunov AA, McKhann GM et al. Cyclophilin D deficiency attenuates mitochondrial and neuronal perturbation and ameliorates learning and memory in Alzheimer's disease. Nat Med 2008; 14: 1097-1105.
59. Guo L, Du H, Yan S, Wu X, McKhann GM, Chen JX et al. Cyclophilin D deficiency rescues axonal mitochondrial transport in Alzheimer's neurons. PLOS One 2013; 8: e54914

cc)(i) $(-)$ Cell Death and Disease is an open-access journal published by Nature Publishing Group. This work is licensed under a Creative Commons Attribution-NonCommercialNoDerivs 3.0 Unported License. The images or other third party material in this article are included in the article's Creative Commons license, unless indicated otherwise in the credit line; if the material is not included under the Creative Commons license, users will need to obtain permission from the license holder to reproduce the material. To view a copy of this license, visit http://creativecommons.org/licenses/ by-nc-nd/3.0/ 